and NIM811 to affect HBV replication and viral particle secretion from the cells.

Method HepG2215 cells, stably transfected with the full HBV genome and supporting the production of both infectious virions and HBsAg particles, and the parent cells (HepG2) were cultured for 7 days (baseline), prior to treatment with DEB025 or NIM811 at $0.25 ; 1.0$ and $5.0 \mathrm{mg} / \mathrm{ml}$. The cells and supernatants were harvested separately at baseline; 6, 24, 48 and $72 \mathrm{~h}$ after addition of cyclophilin inhibitors. HBV DNA levels - both intracellular and in culture supernatants-were quantitated by Taqman qPCR (ABI7500). Western blot and ELISA were used to assess intracellular and secreted HBsAg, respectively. PLC/PRF/5 cells, expressing only HBsAg, were also tested. Cyclophilin expression in the cells was silenced by transfection separately with siRNA for cyclophilins $\mathrm{A}, \mathrm{B}, \mathrm{C}$ or $\mathrm{D}$ to determine the role of individual cyclophilins in HBV replication.

Results Cyclophilin inhibition with either DEB025 or NIM811 significantly reduced cytoplasmic core-particle associated HBV DNA levels in the cells, between 2 and 10-fold as compared with the control cells. The most pronounced reduction of intracellular HBV DNA (by 10-fold at $72 \mathrm{~h}$ ) was observed with DEB025 $5 \mathrm{mg}$ / $\mathrm{ml}$, which was greater than the reduction observed with NIM811. Similarly, DEB025 (at 1 and $5 \mathrm{mg} / \mathrm{ml}$ ) showed a greater impact in reducing $\mathrm{HBV}$ virion secretion in the supernatants, compared with NIM811. HBsAg secretion from the cells was also reduced by up to $50 \%$ when compared to controls. Cyclophilin-A expression was markedly reduced after transfection with corresponding siRNA, which led to a rapid decrease of intracellular HBV DNA by 2 logs. HBV-DNA was reduced further when the cyclophillin-A silenced cultures were treated with NIM811 or DEB025.

Conclusion These results demonstrate that cyclophilin A is directly involved in HBV replication. Cyclophilin inhibition by DEB025 or NIM811 interferes with HBV replication within liver cells and reduces the secretion of infectious virions and HBsAg particles from the cells, with DEB025 having a greater antiviral activity than NIM811.

\section{P44 USE OF INTRALIPID INFUSION TO ANALYSE APOLIPOPROTEIN B (APOB) AND HCV RNA KINETICS IN CHRONIC INFECTION}

doi:10.1136/gutjnl-2011-300857a.44

${ }^{1} \mathrm{D}$ Felmlee, ${ }^{1} \mathrm{D}$ Sheridan, ${ }^{1} \mathrm{~S}$ Bridge, ${ }^{2} \mathrm{C}$ Packard, ${ }^{2} \mathrm{M}$ Caslake, ${ }^{1} \mathrm{G}$ Toms, ${ }^{3} \mathrm{D}$ Neely, ${ }^{1} \mathrm{M}$ Bassendine. ${ }^{1}$ Newcastle University; ${ }^{2}$ Glasgow Royal Infirmary; ${ }^{3}$ Royal Victoria Infirmary

Introduction Production of infectious $\mathrm{HCV}$ is dependent on hepatocytes VLDL assembly, maturation, and secretory machinery. ApoB-100 is the structural apolipoprotein of large VLDL (VLDL1), small VLDL2, and LDL. Although HCV production is dependent on VLDL, chronic HCV infection clinically manifests in lower VLDL and LDL levels, particularly in genotype 3.

Aim To determine the production and clearance rates of apoB and triglyceride (TG) in VLDL1 in chronic HCV infected patients compared to uninfected volunteers. In addition, to observe if altering the VLDL1 kinetics would affect low-density HCV RNA quantities.

Method VLDL1 kinetics were analysed using a protocol involving an IV infusion of a chylomicron-like lipid emulsion (Intralipid) for 120 min to prevent the clearance of VLDL1 by lipoprotein lipase. ${ }^{1}$ Multiple blood samples were taken during and for $4 \mathrm{~h}$ after the infusion. Lipoprotein kinetics were examined by cumulative flotation ultracentrifugation and the clearance of HCV RNA from different density fractions was studied by iodixanol gradient ultracentrifugation. ${ }^{2}$

Results VLDL1 TG production rate was lower for HCV patients $[n=6]$ compared to healthy subjects $1[n=10]$, but the production rate of VLDL1 apoB was similar. Chronic HCV patients cleared Intralipid at a slower rate than uninfected controls.

Plasma HCV RNA accumulated linearly in the serum during the $6 \mathrm{~h}$ experiment $[14 \%$ increase per hour], indicating that Intralipid infusion either stimulated virion production, diminished virion clearance or both. Immediately after the Intralipid infusion ceased, triglyceride cleared exponentially, but at a slower rate than in uninfected individuals. HCV RNA in a very-low density fraction (VLDF, $\mathrm{d}<1.025 \mathrm{~g} / \mathrm{ml}$ ) also immediately cleared, but linearly, parallelling VLDL1 clearance ( $\mathrm{t} 1 / 2=77 \mathrm{~min})$. However, HCV RNA in the high density fraction continued to accumulate $[19.8 \%$ increase per hr] during the post-infusion period.

Conclusion VLDL1 TG production and clearance rates are impaired in patients with chronic HCV infection. HCV associates with large TG-rich lipoproteins in vivo, and clears from the plasma via this route. However, competitive inhibition of lipoprotein clearance results in accumulation of $\mathrm{HCV}$ particles in the vascular compartment, particularly those that lack association with TGrich lipoproteins. Intralipid effectively uncouples the interaction of higher density de novo produced particles, with VLDL. We hypothesise that HCV particles need to transfer onto very low density 'acceptor' particles to facilitate clearance via the remnant pathway.

\section{REFERENCES}

1. Al-Shayii IAR, et al. J Lipid Res 2007:48:2086.

2. Felmlee DJ, et al. Gastro 2010;139:1774.

\section{P45 NATURAL KILLER CELL CYTOTOXICITY IS ENHANCED IN INJECTION DRUG USERS WITH APPARENT RESISTANCE TO HEPATITIS C VIRUS INFECTION}

doi:10.1136/gutjnl-2011-300857a.45

${ }^{1} \mathrm{U}$ Warshow, ${ }^{1} \mathrm{C}$ Sieberhagen, ${ }^{2} \mathrm{D}$ Hegazy, ${ }^{3} \mathrm{E}$ Kaminski, ${ }^{4} \mathrm{~S}$ Knapp, ${ }^{4} \mathrm{~S}$ Khakoo, ${ }^{1} \mathrm{M}$ E Cramp. ${ }^{1}$ Hepatology Research Group, Peninsula College of Medicine \& Dentistry, South West Liver Unit, Derriford Hospital, Plymouth; ${ }^{2}$ Hepatology Research Group, Peninsula College of Medicine \& Dentistry; ${ }^{3} /$ mmunology department, Derriford Hospital, Plymouth; ${ }^{4}$ Department of Hepatology, Division of Medicine, Imperial College, London, UK

Introduction We have identified a cohort of injection drug users (IDU) who, despite long-term high risk sharing of drug injection equipment, remain seronegative and aviraemic for HCV. These exposed uninfected (EU) IDU appear resistant to HCV infection. This resistance is associated with the same Natural Killer (NK) immunoglobulin-like receptor (KIR)/HLA genotype known to favour spontaneous HCV clearance. Whether there is a functional alteration in NK cell cytotoxicity in these individuals is unknown. Aim To investigate cytotoxic function of NK cells in EU.

Method Peripheral blood mononuclear cells (PBMC) were isolated from $16 \mathrm{EU}$ (HCV-Ab positive and HCV-RNA negative), 10 IDU with untreated chronic HCV (cHCV) and five IDU with spontaneous resolution (SR) of HCV (HCV-Ab positive but HCV RNA negative). NK cytotoxicity was assessed against the NK-sensitive $\mathrm{K} 562$ cell line. PBMC incubated for $48 \mathrm{~h}$ with or without interleukin-2 (IL-2) were co-cultured with K562 for $4 \mathrm{~h}$ at an E:T ratio of 10:1. Flow cytometry was used to assess the frequency of NK cells [CD56(+) CD3(-)] in PBMC and cytotoxicity quantified by CFSE/ 7-AAD co-staining and expressed as the percentage of cells lysed. 